\title{
Estudo morfofuncional dos rins de cães da raça Golden Retriever afetados pela distrofia muscular (GRMD) ${ }^{1}$
}

\author{
Dilayla K. Abreu², Carolina Costola-de-Souza ${ }^{3}$, Dayane Alcântara², Elaine A.F. Rodrigues², \\ Karla P.C. Araújo², Paulo C. Maiorka ${ }^{3}$, Maria A. Miglino² e Carlos E. Ambrósio ${ }^{4}$
}

\begin{abstract}
Abreu D.K., Costola-de-Souza C., Alcântara D., Rodrigues E.A.F., Araújo K.P.C., Maiorka P.C., Miglino M.A. \& Ambrósio C.E. 2012. [Morphofunctional study in kidneys of Golden Retriever dogs affected by muscular dystrophy (GRMD).] Estudo morfofuncional dos rins de cães da raça Golden Retriever afetados pela distrofia muscular (GRMD). Pesquisa Veterinária Brasileira 32(10):1067-1072. Setor de Anatomia dos Animais Domésticos e Silvestres, Faculdade de Medicina Veterinária e Zootecnia, Universidade de São Paulo, Av. Prof. Dr. Orlando Marques de Paiva 87, Cidade Universitária, São Paulo, SP 05508-270, Brazil. E-mail: dilaylabreu@usp.br

Duchenne muscular dystrophy (DMD) is a severe myopathy of recessive X-linked character and the most relevant animal study model is the Golden Retriever muscular dystrophy (GRMD). In addition to the severe changes occurring in the striated musculature, several studies show that other structures, including viscera, may prove to be altered in this pathology. Thus, this study aimed to analyze and compare possible structural and functional alterations of the kidney in GRMD dogs. In this study model, it was possible to observe the presence of convex and concave faces, the renal hilum, and the cranial and caudal poles of the kidneys. The organ was surrounded by a fibrous capsule. In a sagittal section of the organ, the presence of the cortical and medullary regions and the renal pelvis were noticed. On microscopic examination, it was possible to identify the medullary and cortical zones and their structures: the renal corpuscles formed by the glomerulus and Bowman's capsule, the proximal and distal convoluted tubules, the collecting ducts, the blood vessels, and the segments of the loops of Henle. The serum creatinine and urea were within normal limits. Thus, according to our results, we may conclude that the affected animals under study showed no structural or functional changes in the kidneys, something which allows us to suggest that, despite the impaired water intake, renal structure remains preserved in GRMD animals.
\end{abstract}

INDEX TERMS: GRMD, kidney, muscular dystrophy.

RESUMO.- A Distrofia Muscular de Duchenne (DMD) é uma miopatia severa de caráter recessivo ligada ao cromossomo $\mathrm{X}$ e o modelo animal de estudo mais relevante é o Golden Retriever Muscular Dystrophy (GRMD). Além das severas alterações que ocorrem na musculatura estriada, muitos

\footnotetext{
${ }^{1}$ Recebido em 3 de agosto de 2012.

Aceito para publicação em 4 de setembro de 2012.

${ }^{2}$ Departamento de Cirurgia, Faculdade de Medicina Veterinária e Zootecnia (FMVZ), Universidade de São Paulo (USP), Rua Prof. Orlando Marques de Paiva 87, São Paulo, SP 05508-000, Brasil. *Autor para correspondência: dilaylabreu@usp.br

${ }^{3}$ Departamento de Patologia Experimental e Comparada, FMVZ-USP, São Paulo, SP.

${ }^{4}$ Departamento de Ciências Básicas, Faculdade de Zootecnia e Engenharia de Alimentos, USP, Campus Pirassununga, Av. Duque de Caxias Norte 225, ZAB, Pirassununga, SP 13635-900, Brasil.
}

estudos mostram que outras estruturas, inclusive viscerais, podem se mostrar alteradas nesta patologia. Desta forma, este trabalho objetivou análisar e comparar possíveis alterações estruturais e funcionais do rim em cães GRMD. Neste modelo de estudo, foi possível observar a presença das faces convexa e côncava, do hilo renal e dos pólos craniais e caudais dos rins. 0 órgão mostrou-se envolto por uma cápsula fibrosa. Em um corte sagital do órgão, notou-se a presença das regiões cortical e medular e da pelve renal. $\mathrm{Na}$ análise microscópica foi possível identificar a zona medular e cortical com suas estruturas: os corpúsculos renais formados pelo glomérulo e pela cápsula de Bowman, os túbulos contorcidos proximais e distais, os ductos coletores, vasos sanguíneos e os segmentos das Alças de Henle. As dosagens séricas de creatinina e uréia encontram-se dentro 
dos limites de normalidade. Desta forma, de acordo com os nossos resultados, podemos concluir que os animais afetados estudados, não apresentaram alterações estruturais ou funcionais dos rins, o que nos permitir sugerir que apesar da ingestão hídrica comprometida, a estrutura renal, mantem-se preservada nos animais GRMD.

TERMOS DE INDEXAÇÃO: GRMD, rim, distrofia muscular.

\section{INTRODUÇÃO}

Distrofia muscular é um termo amplamente utilizado para se referir a qualquer doença primária da musculatura esquelética, que resulta em degeneração progressiva, regeneração limitada e fibrose de miofibrilas (Bergman et al. 2002). A distrofia muscular de Duchenne (DMD) é a forma mais grave, comum e de evolução mais rápida dentre as miopatias hereditárias, sendo letal e progressiva. Trata-se de uma desordem neuromuscular recessiva em humanos associada ao cromossomo $\mathrm{X}$, em uma região denominada Xp21, relacionada a uma mutação no gene responsável pela expressão da proteína distrofina (Caromano 1999, Thor \& Terryborry 2003, Yiu \& Korneberg 2008). Em 65\% ocorre deleção de uma parte do DNA, em 5\% duplicação do gene e em 30\% dos casos mutação de ponto (Caromano 1999, Yiu \& Korneberg 2008).

A DMD humana é geneticamente homóloga à distrofia muscular em cães da raça Golden Retriever Muscular Dystrophy - GRMD), compartilhando seu quadro de miopatia severa e desenvolvimento clínico letal (Vainzof et al. 2008, Ambrósio et al. 2009). Isso justifica o uso dos cães em modelos experimentais para diversos estudos que visam à busca de tratamentos para os meninos acometidos pela doença.

Com a ausência de distrofina na membrana sarcoplasmática, ocorre ruptura da mesma, causando o influxo de cálcio e posterior ativação de protease endógena com a ativação da cascata inflamatória. (Collins \& Morgan 2003). Consequentemente, ocorre necrose e substituição do tecido muscular por tecido fibroso e adiposo (Kornegay et al. 2003).

Além das estruturas musculares, órgãos não musculares também podem estar alterados em pacientes distróficos. Vários estudos realizados discorrem sobre alterações em estruturas internas em camundongos mdx, DMD e GRMD (Moriuchi et al. 1991, Berry et al. 1992, Brazeau et al. 1992, Stein et al. 2002, Grando et al. 2009, Alves et al. 2010, Gerger et al. 2010). Estudos realizados discorreram sobre aumentos de tensão observados na veia porta hepática, bem como flacidez da parede da vesícula biliar ocasionada pela ausência do gene da distrofina em camundongos $m d x$. Além disso, também relataram síndrome de má absorção e processos diarréicos atribuídos à disfunção pancreática em humanos (Nowak et al. 1982, Barohn 1988, Miyatake et al. 1989, Moriuchi et al. 1991, Berry et al. 1992, Brazeau et al. 1992, Stein et al. 2002, Grando et al. 2009).

Brazeau et al. (1992) relataram em seu estudo para a avaliação da eficácia de uma determinada droga que seria utilizada no tratamento das distrofias, que os camundongos mdx estudados apresentaram indícios de disfunção hepática e renal baseados nas alterações séricas encontradas nos exames bioquímicos, bem como durante a necropsia, pela diferença de peso dos órgãos em comparação aos órgãos de animais normais.

Os caninos domésticos são acometidos por diversas doenças renais que podem acarretar insuficiência funcional do órgão, entretanto isso não se traduz necessariamente em uma insuficiência renal, pois esta condição depende da quantidade de parênquima lesionado e da severidade das lesões (Osborne \& Finco 1995).

$\mathrm{Na}$ avaliação da função renal, diversos exames laboratoriais podem ser feitos, entre eles os que indicam glicosúria, proteinúria, cilindrúria e também avaliação das células do epitélio renal no sedimento urinário, podendo indicar lesão renal. Os dois parâmetros mais frequentemente utilizados para avaliar a função renal são as concentrações de uréia e creatinina plasmáticas (Biewenga \& Van Den Bron 1981), porém estes parâmetros mostram-se insatisfatórios uma vez que só se acumulam significativamente no sangue quando já existem $50 \%$ ou mais de néfrons não funcionais (Meyer et al. 1995). Ademais estes valores também podem sofrer influências extra-renais (Meyer et al. 1995).

O nível de uréia sanguínea é um indicativo de lesão renal, pois ela é excretada pelos rins e $40 \%$ é reabsorvida pelos túbulos renais. A mensuração da uréia sanguínea é feita para acompanhamento do paciente já acometido por lesão renal, pois eles se tornam aumentados quando 70 a $75 \%$ dos néfrons estão afuncionais (Bush 2004).

A creatinina é derivada da creatina e da fosfocreatina do metabolismo muscular, uma pequena quantidade é excretada pelos túbulos proximais. 0 nível de creatinina plasmática não é influenciado pela proteína alimentar, catabolismo protéico, sexo, idade ou exercício. A creatinina é usada como um índice da velocidade de filtração glomerular, pois se sabe que existe relação entre a velocidade de filtração glomerular e a concentração de creatinina, a cada redução de $50 \%$ da filtração glomerular a creatinina dobra seu valor (Meyer et al. 1995). 0 aumento da fosfatase alcalina também deve ser levado em conta, podendo ser considerado um indicador precoce de lesão renal ser detectado em lesões menos severas (Heiene et al. 1991).

Neste contexto, e considerando a grande importância da fisiologia renal e dos estudos que utilizam drogas como terapêutica no modelo de estudo, este trabalho teve como principal objetivo verificar a aparência macroscópica dos rins de cães GRMD afetados pela distrofia, bem como avaliar microscopicamente a estrutura renal dos cães que vieram a óbito no canil GRMD - Brasil, em diversos graus de evolução da distrofia muscular.

\section{MATERIAL E MÉTODOS}

Para a realização dos estudos macro e microscópicos, foram utilizados rins formolizados (formol 10\%) de 5 cães GRMD pertencentes ao canil GRMD - BRASIL, Faculdade de Medicina Veterinária e Zootecnia da Universidade de São Paulo, que vieram a óbito entre 8 meses e 4 anos de idade. 0 material estava devidamente identificado, sendo do nosso conhecimento o histórico clínico de cada um dos animais.

Os rins foram dissecados e fotografados com câmera digital 12.1 megapixels. Em seguida, realizou-se a descrição macroscópi- 
ca das estruturas identificadas. A nomenclatura utilizada foi baseada na estabelecida pelo International Committee on Veterinary Gross Anatomical Nomenclature, 1994.

Para a realização da análise microscópica, os rins foram desidratados em uma série crescente de concentração de etanol, diafanizados em xilol, seguidos de inclusão em similar de parafina (Histosec $($ ). Cada bloco foi submetido a microtomia em micrótomo automático (Leica RM2165) obtendo-se cortes longitudinais de aproximadamente $5 \mu \mathrm{m}$. Os cortes, após serem desparafinizados em xilol seguidos de uma série decrescente de etanol, foram corados pela técnica de Hematoxilina e Eosina (HE) realizada segundo metodologia descrita e publicada por Tolosa et al. (2003) e suas características morfológicas foram fotodocumentadas em microscópio de luz (Nikon Eclipse E-800).

As análises bioquímicas séricas foram feitas em amostras do soro obtidas após sinérese de sangue coletado de 12 animais, sendo 4 fêmeas e 8 machos com idade variando de 8 meses a 5 anos. Utilizando o sistema Labtest (LABTEST Diagnostica S.A., Lagoa Santa) para diagnóstico, alíquotas das amostras de soro foram processadas para determinação de creatinina e uréia.

\section{RESULTADOS}

Nos cães adultos GRMD estudados, os rins apresentaram-se definidos, recostados à superfície dorsal da cavidade abdominal. Ao explorar a topografia do órgão, notamos que o mesmo apresenta formato de grão de feijão, com uma face convexa e outra côncava, onde é possível a visualização do hilo renal, no centro da borda medial (Fig. 1A). Adicionalmente, é possível identificar os pólos craniais e caudais e a presença do ureter saindo do hilo renal. Visualiza-se ainda a presença da cápsula fibrosa envolvendo o órgão, sendo facilmente removida da sua superfície (Fig.1B,C).

Com a realização do corte sagital, podemos observar internamente a região cortical e medular, além da pelve renal, com a crista renal bem definida e a vascularização na região córtico-medular. 0 córtex apresenta coloração vermelho-marrom e é radialmente estriado. Na medula podemos observar uma porção externa, próxima ao córtex e uma interna, mais clara, próxima à pelve, que apresenta coloração esbranquiçada. No hilo encontramos a artéria renal, a veia renal e o ureter. (Fig.1C).

$\mathrm{Na}$ análise microscópica foi possível identificar a zona medular, cortical e a cápsula renal envolvendo o órgão. Na Figura 2A observa-se a camada cortical renal composta pelos corpúsculos renais corados, em maior proporção, de roxo e os túbulos contorcidos arrendodados ou ovalados em rosa. Em plano sagital, visualiza-se o corpúsculo renal
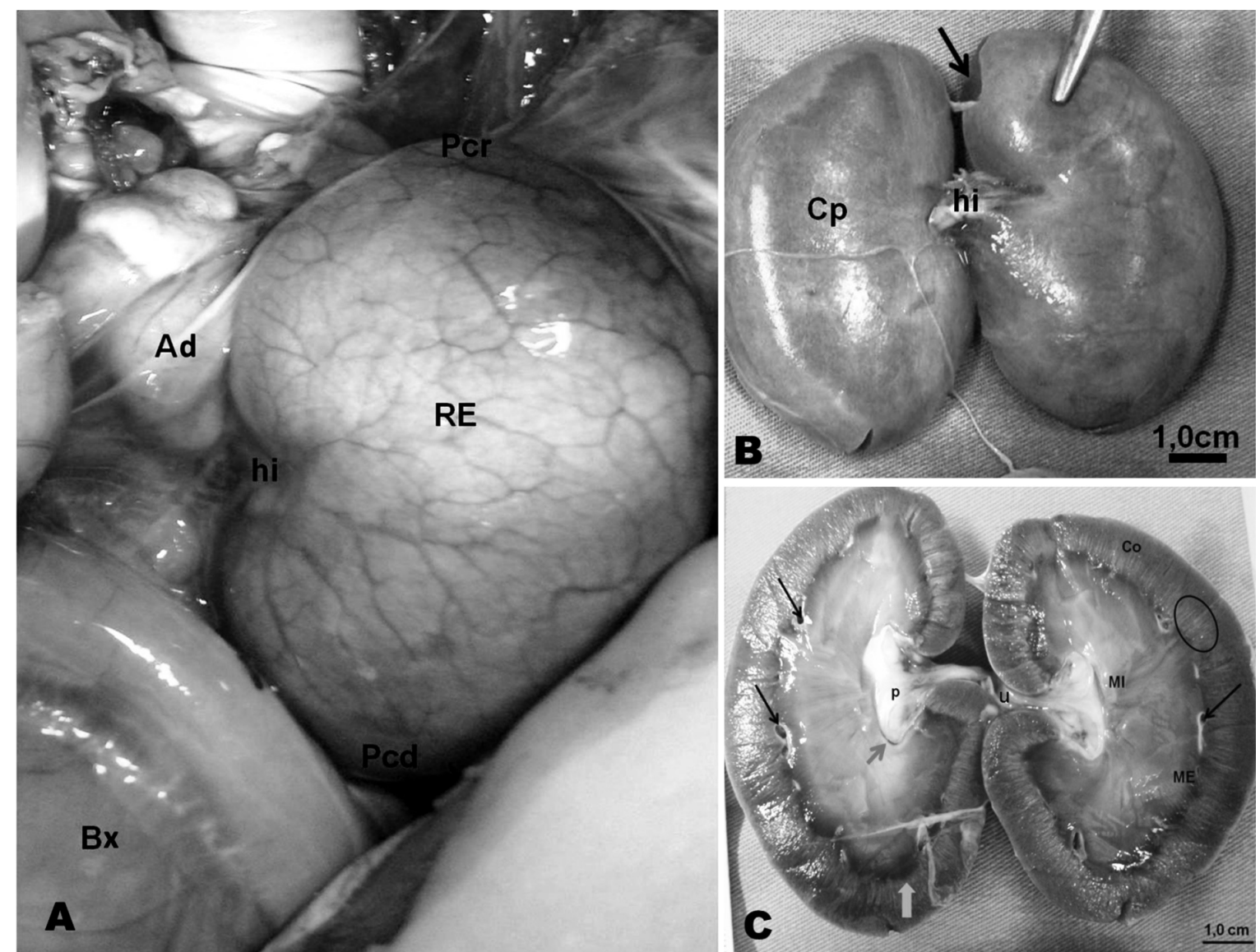

Fig.1. Rim esquerdo de um cão GRMD adulto. (A) Rim esquerdo (RE) com seus pólos cranial (Pcr) e caudal (Pcd), a região de hilo renal (hi), glândula adrenal (Ad), vesícula urinária repleta (Bx). (B) Vista externa após corte sagital do rim. Observar a cápsula renal envolvendo o órgão (Cp) e a região de hilo (hi). Notar como a cápsula é facilmente removida (seta preta). (C) Vista interna após corte sagital do rim, evidenciando as regiões do córtex (Co) e medula, composta pela medula externa (ME) e interna (MI). Notar o aspecto estriado da região cortical (círculo preto) bem como a área de junção córtico-medular (seta laranja), e observar a vascularização sanguínea (seta preta) na região córtico-medular, a crista renal (seta rosa), a pelve renal (p) e o ureter saindo da mesma (u). 

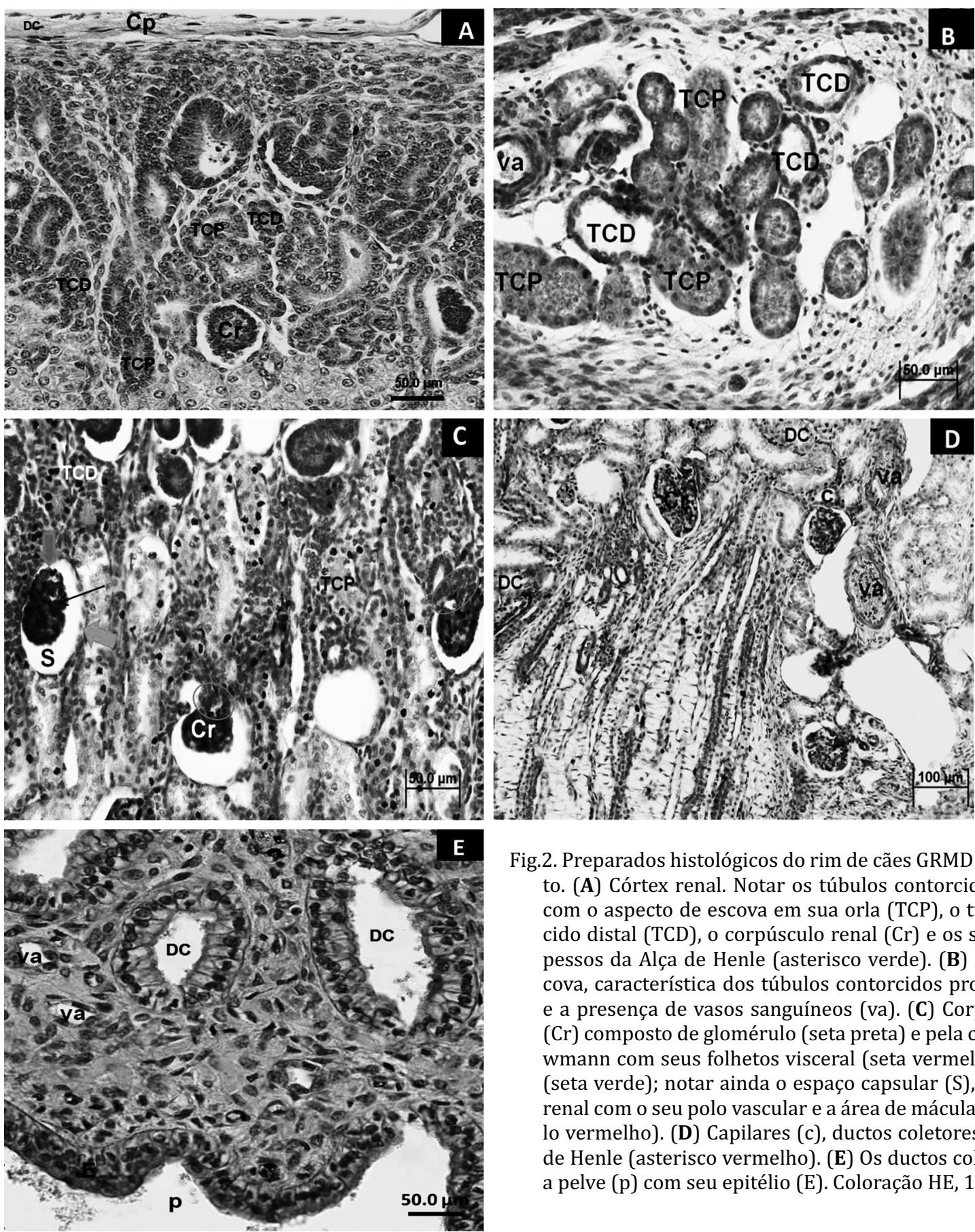

Fig.2. Preparados histológicos do rim de cães GRMD machos adulto. (A) Córtex renal. Notar os túbulos contorcidos proximais com o aspecto de escova em sua orla (TCP), o túbulo contorcido distal (TCD), o corpúsculo renal ( $\mathrm{Cr}$ ) e os segmentos espessos da Alça de Henle (asterisco verde). (B) A orla em escova, característica dos túbulos contorcidos proximais (TCP) e a presença de vasos sanguíneos (va). (C) Corpúsculo renal (Cr) composto de glomérulo (seta preta) e pela cápsula de Bowmann com seus folhetos visceral (seta vermelha) e parietal (seta verde); notar ainda o espaço capsular (S), o corpúsculo renal com o seu polo vascular e a área de mácula densa (círculo vermelho). (D) Capilares (c), ductos coletores (DC) e Alças de Henle (asterisco vermelho). (E) Os ductos coletores (DC) e a pelve (p) com seu epitélio (E). Coloração HE, 10x.

com formato arredondado. Nota-se que os túbulos contorcidos proximais apresentam um citoplasma apical com microvilos que formam uma "orla em escova" em seu lúmen, enquanto que os túbulos contorcidos distais não apresentam esta característica. Observa-se a presença dos segmentos espessos das Alças de Henle, com epitélio cúbico semelhante aos túbulos contorcidos distais. (Fig.2B).

$\mathrm{Na}$ fotomicrografia da região cortical, evidenciou-se o corpúsculo renal, formado pelo glomérulo e pela cápsula de Bowman que possui dois folhetos, o parietal e visceral, que ficam separados pelo espaço capsular. 0 espaço capsular recebe o líquido filtrado pelos capilares e pelo folheto visceral. Foi possível identificar o pólo vascular e a mácula densa. Nota-se que essa região é mais escura, isto se deve a proximidade dos núcleos de suas células (Fig.2C). OPbservamos segmentos delgados das alças de Henle com um epitélio composto por células pavimentosas (Fig.2 D).

$\mathrm{Na}$ camada medular notamos os ductos coletores com seu epitélio composto por células cilíndricas. Notar a região de pelve e seu epitélio (Fig.2E).

No Quadro 1 podemos visualizar os valores referentes à dosagem sérica de creatinina e uréia dos cães afetados pela distrofia muscular com idade variando entre 8 meses e 5 anos. A creatinina apresentou uma concentração sérica média de $0,69 \mathrm{mg} / \mathrm{dL}$ e a ureia de 32,15 U/L. É possível observar que as dosagens encontram-se dentro dos valores de normalidade. 
Quadro 1. Médias, desvios-padrão (DP), valores máximos (Vmax) e valores mínimos (Vmin) referentes à dosagem sérica de uréia e creatinina de cães da raça Golden Retriever afetados pela distrofia muscular

\begin{tabular}{ccccc}
\hline Parâmetro & Média \pm DP & Vmin & Vmax & $\begin{array}{c}\text { Valores de } \\
\text { normalidade }\end{array}$ \\
\hline Creatinina (mg/dL) & $0,69 \pm 0,11$ & 0,42 & 0,96 & $0,5-1,5$ \\
Uréia (mg/dL) & $32,15 \pm 7,99$ & 25 & 56,70 & $21-60$
\end{tabular}

\section{DISCUSSÃO}

O sistema urinário é formado pelos rins, ureteres, bexiga e uretra. Desta forma, a urina formada nos rins é conduzida até a bexiga pelos ureteres e da bexiga, a urina é lançada para o meio exterior pela uretra (Junqueira \& Carneiro 2004).

Comparativamente aos rins dos mamíferos de forma geral, os GRMD também apresentam rins pareados, presentes no retroperitônio, ventrolaterais e adjacentes aos corpos das vértebras lombares e seus processos transversos correspondentes (McGavin \& Zachary 2009). Assim como a anatomia renal de cães saudáveis, os rins dos GRMD são unilobares, em formato de feijão, e coloração avermelhada (Ellenport 1986, Dyce et al. 1997, König et al. 2004, Stickland 2010), corroborando com nossos resultados.

Nossos resultados condizem com os achados de Junqueira \& Carneiro (2004) para rim humano e com os achados de William (1992) e Bacha \& Bacha (2003) sobre o rim canino, sendo que a apresentação da disposição celular é semelhante, e as três camadas, cortical, medular externa e medular interna, mostram-se distintas e de semelhante disposição das estruturas, conforme encontrados em nossos estudos.

Gatti (2007) em um estudo com GRMD relatou que tanto os animais afetados como os portadores da doença, não apresentaram alterações da função glomerular. Sendo assim, o autor descartou uma correlação entre a distrofia muscular e a lesão na musculatura dos vasos renais que pudessem levar a alterações da função do órgão. As mesmas condições foram observadas em nosso estudo, entretanto, os mesmos podem sinalizar ao clínico, conjuntos de procedimentos que podem melhorar a condição e sobrevida dos animais afetados. Apesar da diferença estatística apresentada por Gatti (2007), os valores séricos encontram-se dentro dos limites da normalidade. Os mesmos achados foram evidenciados em nosso estudo com relação à dosagem sérica de creatinina e uréia. No entanto, Gatti (2007) não descartou a possibilidade de existirem alterações subclínicas na função renal destes cães por apresentarem desidratação, o que pode sugerir alguma doença que necessite de maiores informações.

Considerando a dosagem sérica de uréia, os valores encontrados para os cães distróficos se encontram dentro dos parâmetros de normalidade de acordo com Kaneko et al. (1997) que sugere dosagem de 21-60mg/dL e Bush (2004) que sugere dosagem sérica de $30-40 \mathrm{md} / \mathrm{dL}$. É importante ressaltar que os animais se encontravam em jejum no momento das coletas, visto que podem ocorrer aumentos temporários na concentração de uréia após a alimentação (Bush 2004). 0 mesmo foi observado com a dosagem da creatinina sérica, onde todos os animais apresentaram valores dentro dos valores limítrofes de normalidade $(0,5-$ $1,5 \mathrm{mg} / \mathrm{dL}$ ) de acordo com Kaneno et al. (1997). Morini et al. (2011) realizou um estudo com cadelas portadoras da distrofia muscular e evidenciou que as dosagens séricas de uréia e creatinina também se encontraram dentro dos parâmetros de normalidade.

\section{CONCLUSÃO}

De acordo com nossos resultados, não foram encontradas alterações estruturais macroscópicas ou microscópicas mediante estudo histológico com coloração hematoxilina-eosina nos rins de cães GRMD estudados.

Agradecimentos.- A colega do Setor de Anatomia, pela valiosa ajuda neste trabalho, Juliana Casals.

\section{REFERÊNCIAS}

Alves F.R., Abreu D.K., Brólio M.P., Fernandes R.A., Souza C.C., Wenceslau C.V., Ambrósio C.E., Guerra R.R. \& Miglino M.A. 2010. Radiologic images at thoracic cavity of golden retriever dogs affected by muscular dystrophy. Vet. RadiolUltrasound 51:220

Ambrósio C.E., Fadel L., Gaiad T.P., Martins D.S., Araújo K.P.C., Zucconi E., Brólio M.P., Giglio R.F., Morini A.C., Santos T.C., Jazedje T., Froes T.R., Feitosa M.L.T., Valadares M., Beltrão-Braga P.C.B., Meirelles F.V. \& Miglino M.A. 2009. Identification of three distinguishable phenotypes in golden retriever muscular dystrophy (GRMD). Gen. Mol. Res. 8:389-396.

Bacha W.J. \& Bacha L.M. 2003. Atlas Colorido de Histologia Veterinária. 2nd ed., Roca, São Paulo. 457p.

Banks W.J. 1992. Sistema urinário, p.481-498. In: Banks W.J. (Ed.), Histologia Veterinária Aplicada. 2a ed. Editora Manole, São Paulo. 629p.

Barohn R.J., Levine E.J., Olson J.O. \& Mendell J.R. 1988. Gastric hypomotility in Duchenne's muscular dystrophy. N. Engl. J. Med. 319:15-18.

Bergman R.L., Inzana K.D., Monroe W.E., Shell L.G., Liu L.A., Engvall E. \& Shelton G.D. 2002. Dystrophin-deficient muscular dystrophy in a Labrador Retriever. J. Am. Anim. Hosp. Assoc. 38:255-261.

Berry C.R., Gaschen F.P. \& Ackerman N. 1992. Radiographic and ultrasonographic features of hypertrophic feline muscular dystrophy in two cats. Vet. Radiol. Ultrasound 33:357-364.

Biewenga W.J. \& Van Den Bron W.E. 1981. Assessment of glomerular filtration rate in dogs with renal insufficiency: analyses of the $51 \mathrm{Cr}$-EDTA clearance and its relation to the plasma concentrations of urea and creatinine. Res. Vet. Sci. 30:158-160.

Brazeau G.A., Mathew M. \& Entrikin R.K. 1992. Serum and organ indices of the mdx dystrophic mouse. Res. Commun. Chem. Pathol. Pharmacol. $77: 179-189$

Bush B.M. 2004. Interpretação de Resultados Laboratoriais para Clínico de Pequenos Animais. Roca, São Paulo. 368p.

Caromano F.A. 1999. Características do Portador de Distrofia Muscular de Duchenne (DMD): revisão. Arq. Ciênc. Saúde Unipar 3:211-218.

Collins C.A. \& Morgan J.E. 2003. Duchenne's muscular dystrophy: animal model used to investigate pathogenesis and develop therapeutic strategies. Int. J. Exp. Pathol. 84:165-172.

Dyce K.M., Sack W.O. \& Wensing C.J.G. 2012. The pelvis and reproductive organs of the dog and cat, p454-475. In: Dyce K.M., Sack W.O. \& Wensing C.J.G. (Eds), Tratado de Anatomia Veterinária. $4^{\text {th }}$ ed. Saunders Elsevier, St. Louis. 139 p.

Ellenport C.R. 1986. Aparelho urogenital do carnívoro, p.1481-1493. In: Getty R. (Ed.), Sisson/Grossman - Anatomia dos Animais Domésticos. 5ª ed.. Guanabara Koogan, Rio de Janeiro. 1445p.

Gatti A. 2007. Estudo da função glomerular em Golden Retriever normais, portadores e afetados pela distrofia muscular progressiva (GRMD). Dis- 
sertação de Mestrado em Anatomia dos Animais Domésticos e Silvestres, Faculdade de Medicina Veterinária e Zootecnia, Universidade de São Paulo, São Paulo, SP. 97p.

Gerger A.A.C., Souza C.C., Martins D.S., Gaiad T.P., Brolio M.P., Luppi M.M.C.P., Ambrósio C.E. \& Miglino M.A. 2010. Alterações do trato digestório de cães da raça Golden Retriever afetados pela distrofia muscular. Pesq. Vet. Bras. 30:1064-1070.

Grando A.P., Mariana A.N.B., Miglino M.A., Sterman F.A., Zatz M., Kanayama L.M., Feitosa M.L.T., Martins D.S., Morini A.C., Passos J., Fadel L. \& Ambrósio C.E. 2009. Ultra-sonografia abdominal e pélvica em cães da raça Golden Retriever sadios, portadores e afetados pela distrofia muscular progressiva. Ciência Rural 39:123-128.

Heiene R., Biewenga W.J. \& Koeman J.P. 1991. Urinary alkaline phosphatase and $\gamma$-glutamyl transferase as indicators of acute renal damage in dogs. J. Small Anim. Pract. 32:521-524.

Junqueira L.C. \& Carneiro J. 2004. Histologia Básica. 10ª ed. Guanabara Koogan, Rio de Janeiro. 371p.

Kaneko J.J. 1997. Serum proteins and dysproteinemias, p.117-138. In: Kaneko J.J., Harvey J.W. \& Bruss M.L. (Eds), Clinical Biochemistry of Domestic Animals. $5^{\text {th }}$ ed.. Academic Press, San Diego. 932p.

König H.E., Ruberte J. \& Liebich H.G. 2004. Aparelho urogenital, p.103-118. In: König H.E., Maierl J., Liebich H.G. (Eds), Anatomia dos Animais Domésticos - Órgãos e Sistemas. 3 a ed. Artmed, Porto Alegre. 70p.

Kornegay J.N., Cundiff D.D., Bogan D.J., Bogan J.R. \& Okamura C.S. 2003. The cranial sartorius muscle undergoes true hypertrophy in dogs with golden retriever muscular dystrophy. Neuromuscular Disorders 13:493500 .

McGavin M.D. \& Zachary J.F. 2007. Pathologic Basis of Veterinary Disease. $4^{\mathrm{a}}$ ed. Mosby Elsevier, China.
Meyer D.J., Coles E.H. \& Rich L.J. 1995. Medicina de Laboratório Veterinária: interpretação e diagnóstico. Roca, São Paulo. 135p.

Miyatake M., Miike T., Zhao J., Yoshioka K., Uchino M. \& Usuku G. 1989. Possible systemic smooth muscle layer dysfunction due to a deficiency of dystrophin in Duchenne muscular dystrophy. J. Neurol. Sci. 93:11-17.

Morini A.C., Brolio M.P., Millano A.M.O.G., Braggio L.Z., Martins D.S., Perecin F., Ambrósio C.E. \& Miglino M.A. 2011. Existem diferenças nos parâmetros hematológicos e bioquímicos séricos entre fêmeas normais e portadoras do modelo experimental GRMD (Golden Retriever Muscular Dystrophy)? Pesq. Vet. Bras. 31:94-98.

Moriuchi T., Fujii Y., Kagawa N. \& Hizawa K. 1991. Autopsy study on the heart, liver, kidney and brain in Duchenne muscular distrophy. Tokushima J. Exp. Med. 38:5-13.

Nowak T.V., Ionasescu V. \& Anuras S. 1982. Gastrointestinal manifestations of the muscular dystrophies. Gastroenterol. 82:800-810.

Osborne C.A. \& Finco D.R. 1995. Canine and Feline Nephrology and Urology. Media, Williams and Wilkins, Baltimore. 960p.

Stein M.T., Tipnis N.A. \& Schultz P. 2002. Fatigue, decrease interest in play, motor delay, and elevated liver function tests in a 4-year-old boy. J. Dev. Behav. Pediatr. 23:37-41.

Stickland D.J. 2010. Atlas Colorido de Anatomia Veterinária do Cão e Gato. $2^{\mathrm{a}}$ ed. Editora Elsevier, Rio de Janeiro. 261p.

Thor G. \& Terryborry J. 2003. Muscular dystrophy: Recent milestones. Drug and Market Development 14:115-123.

Vainzof M., Ayub-Guerrieri D., Onofre P.C.G., Martins P.C.M., Lopes V.F., Zilberztajn D., Maia L.S., Sell K. \& Yamamoto L.U. 2008. Animal models for genetic neuromuscular diseases. J. Mol. Neurosci. 34:241-248.

Yiu E.M. \& Kornberg A.J. 2008. Duchenne muscular dystrophy. Neurology India 56:236-247. 